\title{
Characterization of novel stress degradation products of Bempedoic acid and Ezetimibe using UPLC-MS/MS: development and validation of stability-indicating UPLC method
}

\author{
Anuradha Vejendla ${ }^{*}$, Subrahmanyam Talari ${ }^{2,3}$, G. Ramu ${ }^{3}$ and Ch Rajani ${ }^{4}$
}

\begin{abstract}
Background: A receptive and easily comprehended technique was evolved for simultaneous assessment of Bempedoic acid and Ezetimibe and its impurities characterized by UPLC-MS/MS.

Results: This technique involves chromatographic separation with a $C_{18}$ column of water symmetry $(150 \mathrm{~mm} \times 4.6 \mathrm{~mm}, 3.5 \mu \mathrm{m})$. A mobile phase of $0.1 \%$ OPA (orthophosphoric acid) and acetonitrile in 50:50 v/v with $1 \mathrm{~mL} / \mathrm{min}$ flow rate and ambient temperature was used. UV observation was taken at $230 \mathrm{~nm}$. The recoveries, linearity, and quantification limits were found to be within the acceptable limit.
\end{abstract}

Conclusions: This technique was successfully tested with UPLC-MS to confirm the chemical structures of newly formed degradation products of Bempedoic acid and Ezetimibe and stress studies as per ICH Q2 (R1) guidelines.

Keywords: Bempedoic acid, Ezetimibe, Validation, Characterization, UPLC, UPLC-MS

\section{Background}

Bempedoic acid is a pharmaceutical medicine utilized for the therapy of high cholesterol (high blood cholesterol levels) [1-3]. Bempedoic acid is approved for the treatment of hypercholesterolemia and therefore the highest tolerated statin therapy in adults with heterozygous [4], with hypercholesterolemia [5, 6], or with established atherosclerotic cardiovascular disorder $[7,8]$, who need additional lowering of LDL cholesterol $[9,10]$. The most common adverse effects in clinical trials are muscle spasms, pain in the rear or within the limb, gout $[11,12]$, and gastrointestinal problems [13] like diarrhea [14, 15].

\footnotetext{
*Correspondence: vanuradha372@gmail.com

1 Department of Chemistry, Vignan Degree College, Guntur, AP 522009, India

Full list of author information is available at the end of the article
}

A less common but more serious effect was tendon rupture [16] within the structure of the shoulder, the biceps tendon, or the Achilles tendon [17].

Ezetimibe is a pharmaceutical drug unused and treats high blood cholesterol and certain other lipid abnormalities. Generally, it is used alongside dietary changes and a statin $[18,19]$. It is preferred low in statin. It is taken orally. It is also available within the fixed combinations of Ezetimibe/Simvastatin, Ezetimibe/Atorvastatin, and Ezetimibe/Rosuvastatin. Usual consequences include upper respiratory infections, joint pain, diarrhea, and body exhaustion. Serious side effects include anaphylaxis [20, 21], liver problems, depression, and muscle breakdown. Its usage in pregnancy and breastfeeding [22, 23] is unsafe. Ezetimibe lowering the cholesterol involvement the intestines (Fig. 1). The experiments provided details on the conditions under which the drug was unstable to 

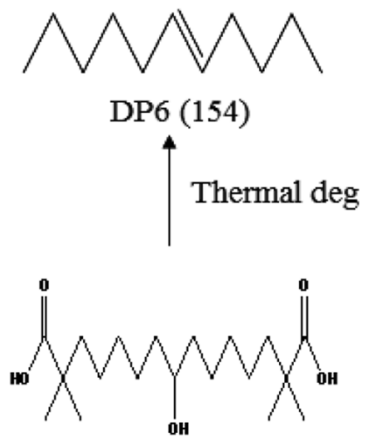

Bempedoic acid
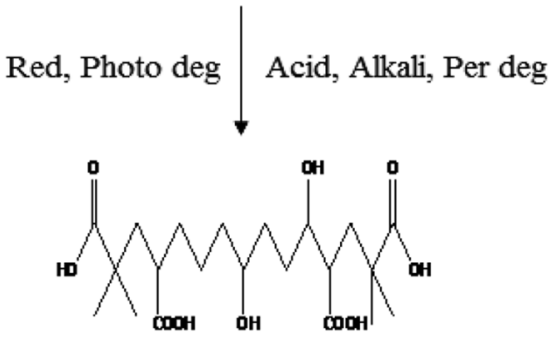

DP1 (449)

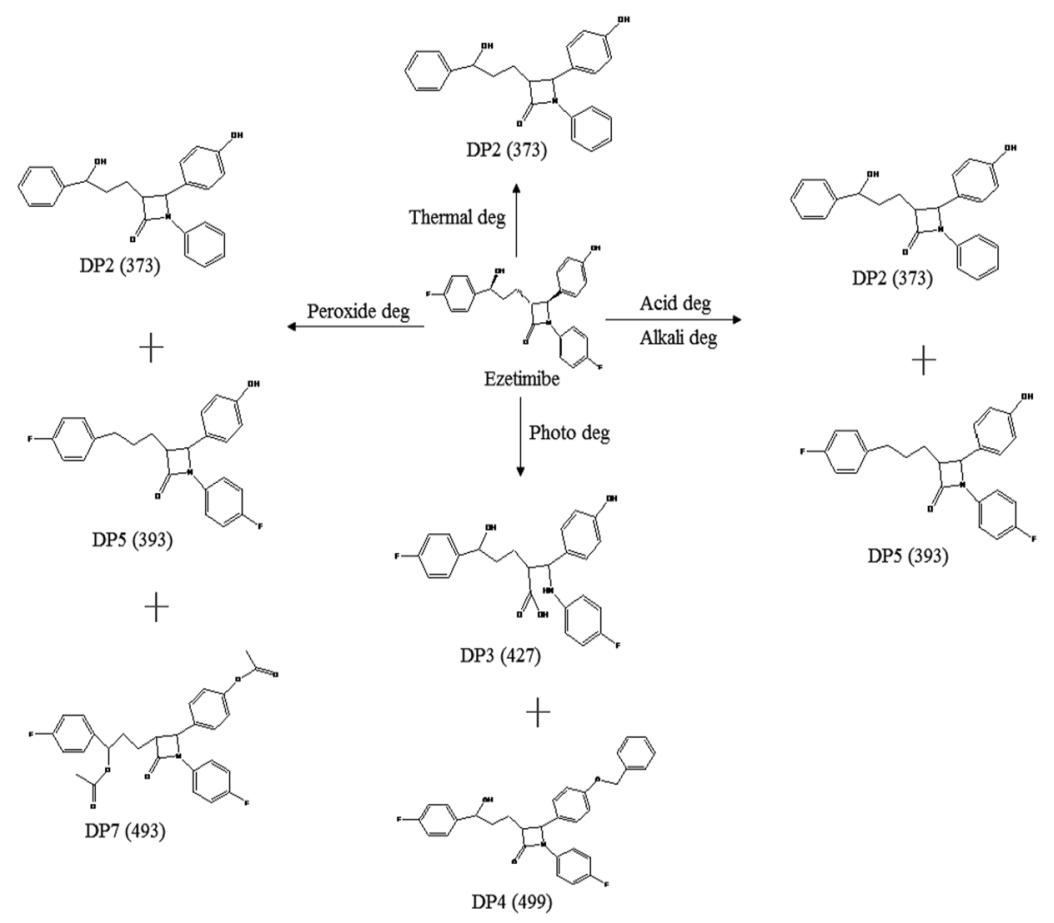

A

B

Fig. 1 Schematic representation of degradation products of $\mathbf{A}$ Bempedoic acid and $\mathbf{B}$ Ezetimibe

prevent possible instability, and suitable steps were taken during formulation.

\section{Methods}

\section{Reagents and chemicals}

Acetonitrile (HPLC mark), orthophosphoric acid (HPLC mark), and water (HPLC mark) were obtained from Merck India Ltd., Worli, Mumbai, India. APIs of Bempedoic acid (purity 99.8\%) and Ezetimibe (purity 99.9\%) were obtained from Cipla Pharmaceutical Company, Mumbai.

\section{Instrumentation}

UPLC

A chromatographic software of empower version 2 was used. Waters Acquity UPLC with a quaternary pump and PDA detector with empower 2.0 software was employed.

\section{UPLC and MS/MS conditions}

The chromatographic process involved the column of symmetry $\mathrm{C}_{18}(150 \times 4.6 \mathrm{~mm}, 3.5 \mu)$ with ambient temperature. An isocratic elution containing $50 \%$ of $0.1 \%$ OPA and $50 \%$ of acetonitrile was used as mobile phase, and the flow rate of $1 \mathrm{~mL} / \mathrm{min}$ with a dose volume of $20 \mu \mathrm{L}$ was employed in UPLC.
In the forced degradation study, UPLC was connected to a mass spectrophotometer with the conditions and the splitter placed before the ESI source, allowing entry of only $35 \%$ of an eluent. The standard operating source conditions for MS scan of Bempedoic acid and Ezetimibe on positive ESI mode were optimized as follows: The fragmented voltage was set at $80 \mathrm{~V}$, the capillary was set at $3000 \mathrm{~V}$, the skimmer was set at $60 \mathrm{~V}$, nitrogen was used as drying and nebulizing gas (45psi), and highly filtered nitrogen gas was used as collision gas.

\section{Preparation of standard solution}

Accurately weighed180 mg of Bempedoic acid and $10 \mathrm{mg}$ of Ezetimibe were transferred into a $100-\mathrm{mL}$ volumetric flask, and $70 \mathrm{~mL}$ of diluent was added and sonicated to dissolve it. Then, the volume was made up to the mark with diluent. Further, diluted $5 \mathrm{~mL}$ of the above solution was transferred into a $50-\mathrm{mL}$ volumetric flask with diluent. And concentration of Bempedoic acid is $180 \mu \mathrm{g} / \mathrm{mL}$ and Ezetimibe is $10 \mu \mathrm{g} / \mathrm{mL}$.

\section{Preparation of sample solution}

The samples were prepared by dissolving the finely ground tablets powder equivalent to $180 \mathrm{mg}$ of Bempedoic acid and $10 \mathrm{mg}$ of Ezetimibe sample, and they were transferred into a 100-mL volumetric flask, and $70 \mathrm{~mL}$ 
of diluents was added, ultrasonicated for $15 \mathrm{~min}$, and diluted up to $100 \mathrm{~mL}$ mark with diluents. Further, diluted $5 \mathrm{~mL}$ of the sample stock solution was transferred into a $50-\mathrm{mL}$ volumetric flask with diluents. Finally, the solution was filtered by utilizing a $0.45-\mu \mathrm{m}$ syringe before injecting into the LC column.

\section{Method validation}

The systematic technique UPLC was confirmed by evaluating the parameters such as system suitability, linearity, accuracy, the limit of detection, the limit of quantification, and robustness, and therefore, the results were found to be within the suitable range of $\mathrm{ICH}$ requirements.

\section{System suitability}

To check the system performance, we used the parameters such as USP tailing, USP plate count, and percentage of relative variance.

\section{Linearity and accuracy}

Linearity was studied by using standard solutions of Bempedoic acid and Ezetimibe at several dilution levels $(10 \%, 25 \%, 50 \%, 75 \%, 100 \%, 125 \%, 150 \%$, and $200 \%)$. Accuracy was studied in three different dilution levels of $50 \%, 100 \%$, and $150 \%$. Finally, $\%$ of recovery and $\%$ of RSD were calculated.

\section{Precision}

Precision is of three types, namely

System Precision Reference standard solution of Bempedoic acid and Ezetimibe was injected six times and \% RSD was calculated .

Method Precision Three levels of sample solutions of Bempedoic acid and Ezetimibe with concentrations of 90, $5 \mu \mathrm{g} / \mathrm{mL}$ (50\%), 180, $10 \mu \mathrm{g} / \mathrm{mL}$ (100\%), and 270, $15 \mu \mathrm{g} /$ $\mathrm{mL}(150 \%)$ were injected and \% recovery and \% RSD were calculated.

Intermediate Precision Three levels of sample solutions of Bempedoic acid and Ezetimibe with concentrations of $90,5 \mu \mathrm{g} / \mathrm{mL}(50 \%), 180,10 \mu \mathrm{g} / \mathrm{mL}(100 \%)$, and 270 , $15 \mu \mathrm{g} / \mathrm{mL}(150 \%)$ were injected in different days by using different columns. Then, \% recovery and \% RSD were calculated.

\section{Robustness}

This technique was studied by changing the flow of $\pm 0.02 \%$, organic phase of $\pm 10 \%$, and wavelength of $\pm 5 \mathrm{~nm}$.

\section{$\angle O D$ and $L O Q$}

LOD means little quantity of analyte during a sample which will be detected, while LOQ explains the little quantity of analyte during a sample which will be observed with tolerable precision accuracy. The limit of detection and limit of quantification for Bempedoic acid and Ezetimibe were determined by injecting progressively low concentrations of ordinary solutions using the developed UPLC method. The limit of detection and limit of quantification were calculated as $3 \mathrm{~s} / \mathrm{n}$ and $10 \mathrm{~s} / \mathrm{n}$, respectively, as per $\mathrm{ICH}$ guidelines where $\mathrm{s} / \mathrm{n}$ indicates the signal-to-noise.

$$
\begin{aligned}
& \text { LOD }=3.3 \times \text { Standard deviation/Slope } \\
& \text { LOQ }=10 \times \text { Standard deviation/Slope } .
\end{aligned}
$$

\section{Stress degradation}

Stress degradation will not interfere between the peaks obtained for the chromatograms of forced degradation preparations. Stress degradation learnings were performed as reported by ICH guidelines Q1 (A) $R_{2}$. The degradation peaks should be separated from one another, and therefore, the resolution between the peaks should be a minimum of 1.0. Therefore, the peak purity of the principle peak shape was passed. The forced degradation work was performed by different kinds of stresses to get the degradation of about $20 \%$.

\section{Acid degradation}

In acid degradation, the sample having $5 \mathrm{~mL}$ of $1 \mathrm{~N} \mathrm{HCl}$ was transferred into a $100 \mathrm{~mL}$ volumetric flask and the flask was heated in a water bath at $60{ }^{\circ} \mathrm{C}$ for $30 \mathrm{~min}$, allowed to cool to room temperature, and neutralized with $5 \mathrm{~mL}$ of $1 \mathrm{~N} \mathrm{NaOH}$. Then, it was made up to the mark with diluent. Further, diluted $5 \mathrm{~mL}$ of the above solution was transferred into a $50-\mathrm{mL}$ volumetric flask with diluent and then filtered and injected into UPLCMS system.

\section{Alkali degradation}

In alkali degradation, the sample having $5 \mathrm{~mL}$ of $1 \mathrm{~N}$ $\mathrm{NaOH}$ was transferred into a $100-\mathrm{mL}$ volumetric flask and the flask was heated in a water bath at $60{ }^{\circ} \mathrm{C}$ for $30 \mathrm{~min}$, allowed to cool to room temperature, and neutralized with $5 \mathrm{~mL}$ of $1 \mathrm{~N} \mathrm{NaOH}$. Then, it was made up to the mark with diluent. Further, diluted $5 \mathrm{~mL}$ of the above solution was transferred into a $50-\mathrm{mL}$ volumetric flask with diluent and then filtered and injected into UPLCMS system.

\section{Peroxide degradation}

In peroxide degradation, sample having $5 \mathrm{~mL}$ of $30 \%$ hydrogen peroxide was transferred into a $100-\mathrm{mL}$ volumetric flask. After that, the flask was heated in a water bath at $60{ }^{\circ} \mathrm{C}$ for $30 \mathrm{~min}$. and allowed to cool to room 
temperature. Then, it was made up to the mark with diluent, and further, diluted $5 \mathrm{~mL}$ of the above solution was transferred into a $50-\mathrm{mL}$ volumetric flask with diluent and then filtered and injected into UPLC-MS system.

\section{Reduction degradation}

In reduction degradation, sample having $5 \mathrm{~mL}$ of $10 \%$ sodium bisulfate solution was transferred into a $100-\mathrm{mL}$ volumetric flask. The flask was heated in a water bath at $60{ }^{\circ} \mathrm{C}$ for $30 \mathrm{~min}$ and allowed to cool to room temperature. Then, it was made up to the mark with diluent, and further, diluted $5 \mathrm{~mL}$ of the above solution was transferred into a 50-mL volumetric flask with diluent and then filtered and injected into UPLC-MS system.

\section{Thermal degradation}

In thermal degradation, 1gm sample powder was weighed in a Petri dish and exposed to dry heat at $105^{\circ} \mathrm{C}$ for $6 \mathrm{~h}$. After that, equivalent weight of $180 \mu \mathrm{g} / \mathrm{mL}$ of Bempedoic acid and $10 \mu \mathrm{g} / \mathrm{mL}$ of Ezetimibe sample was weighed, transferred into a $100-\mathrm{mL}$ volumetric flask, and dissolved in a diluent. Then, it was made up to the mark with diluent. Further, diluted $5 \mathrm{~mL}$ of the above solution was transferred to a $50-\mathrm{mL}$ volumetric flask with diluent.

\section{Photolytic degradation}

In photolytic degradation, tablets were ground finely into powder form and $1 \mathrm{gm}$ sample was exposed to photolight UV $200 \mathrm{~W}$-hrs and fluorescence light 1.2 million lux-hours. After that, equivalent weight of $180 \mu \mathrm{g} / \mathrm{mL}$ of Bempedoic acid and $10 \mu \mathrm{g} / \mathrm{mL}$ of Ezetimibe sample was weighed, transferred into a $100-\mathrm{mL}$ volumetric flask, and dissolved in a diluent. Then, it was made up to the mark with diluent. Further, diluted $5 \mathrm{~mL}$ of the above solution was transferred into a 50-mL volumetric flask with diluent.

\section{Results}

An isocratic elution of Bempedoic acid and Ezetimibe involved symmetry $\mathrm{C}_{18}$ column with a flow rate of $1 \mathrm{~mL} /$ min, and ambient temperature was maintained within the column. A mobile phase of $0.1 \%$ OPA and acetonitrile in 50:50 v/v was used. UV observation was taken at $230 \mathrm{~nm}$.

\section{System suitability}

The standard solution of Bempedoic acid $(180 \mu \mathrm{g} / \mathrm{mL})$ and Ezetimibe $(10 \mu \mathrm{g} / \mathrm{mL})$ was injected into the UPLC system, and the chromatogram of UPLC is shown in Fig. 2. \%RSD was calculated by using the peak areas, and the results were found to be within the acceptable limit. Results of system suitability are shown in Table 1.

\section{Specificity}

Specificity was not used to test the power of the assay of the method but to eliminate the consequences of all interfering substances in Bempedoic acid and Ezetimibe peak results, specifically by comparing the chromatograms

Table 1 System suitability results

\begin{tabular}{|c|c|c|c|c|}
\hline \multirow[t]{2}{*}{ S. no. } & \multirow{2}{*}{$\begin{array}{l}\text { System } \\
\text { suitability } \\
\text { parameter }\end{array}$} & \multirow{2}{*}{$\begin{array}{l}\text { Acceptance } \\
\text { criteria }\end{array}$} & \multicolumn{2}{|l|}{ Drug name } \\
\hline & & & $\begin{array}{l}\text { Bempedoic } \\
\text { acid }\end{array}$ & Ezetimibe \\
\hline 1 & $\%$ RSD & NMT 2.0 & 0.11 & 0.27 \\
\hline 2 & USP Tailing & NMT 2.0 & 1.03 & 1.01 \\
\hline 3 & USP plate count & NLT 2000 & 3111 & 6605 \\
\hline
\end{tabular}

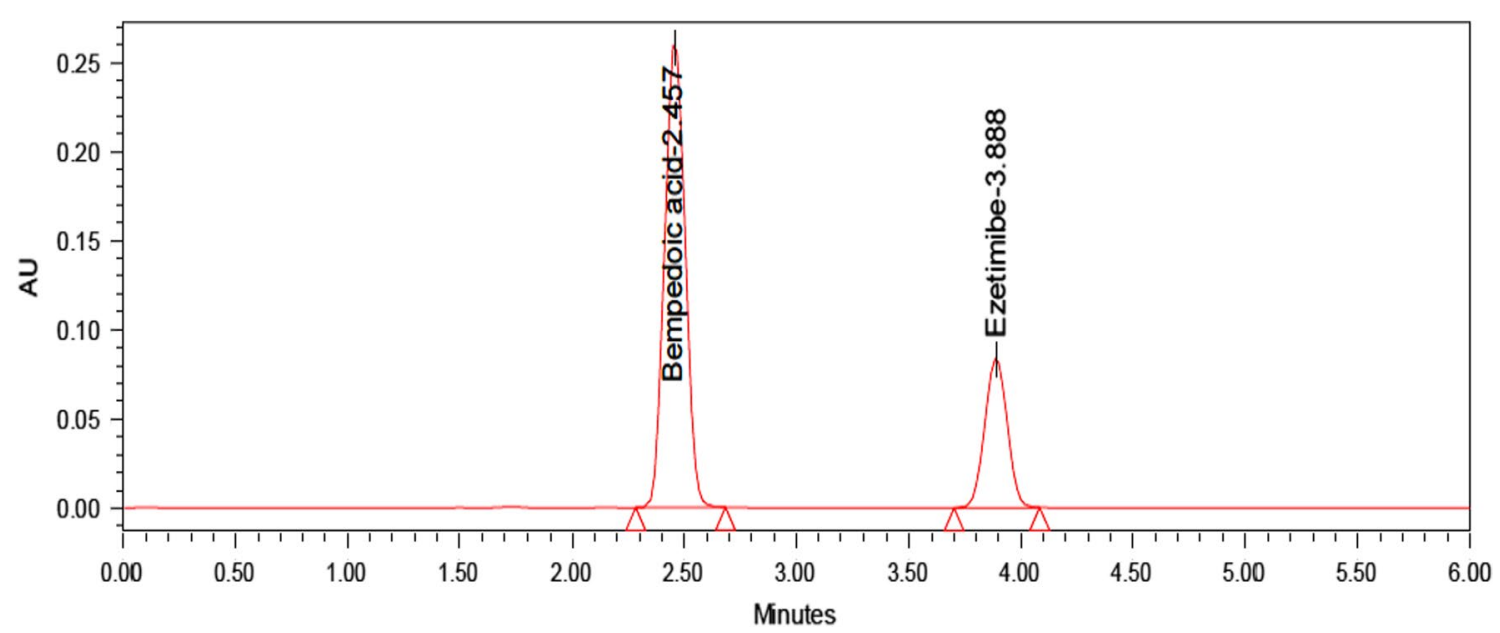

Fig. 2 Standard chromatogram of UPLC 
of the blank samples presented in Fig. 3. The justified technique exhibited that the selected drugs were eluted without the involvement of peaks that occurred by the excipients in the market products.

\section{Linearity}

Linearity of the developed test method was proven by preparing a series of linearity of solutions containing Bempedoic acid and Ezetimibe at eight different concentrations ranging from Bempedoic acid 18-360 $\mu \mathrm{g} / \mathrm{mL}$ (18, $45,90,135,180,225,270$, and $360 \mu \mathrm{g} / \mathrm{mL}$ ) and Ezetimibe $1-20 \mu \mathrm{g} / \mathrm{mL}(1,2.5,5,7.5,10,12.5,15$, and $20 \mu \mathrm{g} / \mathrm{mL})$. The calibration curves were linear throughout the concentration series of Bempedoic acid and Ezetimibe. The values of linearity are listed in Table 2 and Fig. 4. The coefficient of correlation values of both analytes Bempedoic acid and Ezetimibe were 0.9997 and 0.99964 in the calibration curve, respectively .

\section{Accuracy}

Accuracy of Bempedoic acid and Ezetimibe depends on recovery studies, which were administered at three different dilution levels $(50 \%, 100 \%$, and $150 \%)$. APIs with concentrations of 90, 180, $270 \mu \mathrm{g} / \mathrm{mL}$ of Bempedoic acid and 5, 10, $15 \mu \mathrm{g} / \mathrm{mL}$ of Ezetimibe were prepared. According to the test procedure, the test solutions were injected as three preparations of each spike level and therefore the assay was performed. The shared recovery values were observed to be within the range of $98 \%-102 \%$, and the results are shown in Table 3.

\section{Precision}

The precision of this analysis was assessed in terms of method and intermediate variations. The intraday studies
Table 2 UPLC results of linearity

\begin{tabular}{llllll}
\hline Linearity & \multicolumn{2}{l}{ Bempedoic acid } & & \multicolumn{2}{l}{ Ezetimibe } \\
\cline { 2 - 3 } & Conc. $(\boldsymbol{\mu g} / \mathbf{m l})$ & Area & & Conc. $(\boldsymbol{\mu g} / \mathbf{m l})$ & Area \\
\hline Linearity-10\% & 18 & 382,238 & & 1 & 219,908 \\
Linearity-25\% & 45 & 818,812 & & 2.5 & 541,877 \\
Linearity-50\% & 90 & $1,655,675$ & & & $1,089,663$ \\
Linearity-75\% & 135 & $2,463,729$ & & 7.5 & $1,533,475$ \\
Linearity-100\% & 180 & $3,255,329$ & & 10 & $2,188,257$ \\
Linearity-125\% & 225 & $4,003,213$ & & 12.5 & $2,607,096$ \\
Linearity-150\% & 270 & $4,869,046$ & & 15 & $3,134,284$ \\
Linearity-200\% & 360 & $6,486,358$ & & 20 & $4,233,526$ \\
Slope & $17,903.72$ & & & $210,294.97$ & \\
Intercept & $27,530.84$ & & & $10,156.17$ & \\
CC & 0.99992 & & & 0.99964 & \\
\hline
\end{tabular}

were calculated by executing three levels of sample solutions of Bempedoic acid and Ezetimibe with concentrations of $90,5 \mu \mathrm{g} / \mathrm{mL}$ (50\%), $180,10 \mu \mathrm{g} / \mathrm{mL}(100 \%)$, and $270,15 \mu \mathrm{g} / \mathrm{mL}(150 \%)$ in an equivalent day under the equivalent experimental conditions. Intermediate precision of the tactic was administered within the same laboratory by studying the analysis with different days and different columns. The tactic was very precise, and RSD values were found to be $<2 \%$. Good recoveries $(98$ to $102 \%$ ) of the selected drugs were obtained at each attached concentration and showed that the tactic was accurate. The results are given in Table 4 .

\section{LOD and LOQ}

LOD and LOQ were separately determined by the calibration curve method; LOD and LOQ of the compounds were calculated by injecting continuous lower

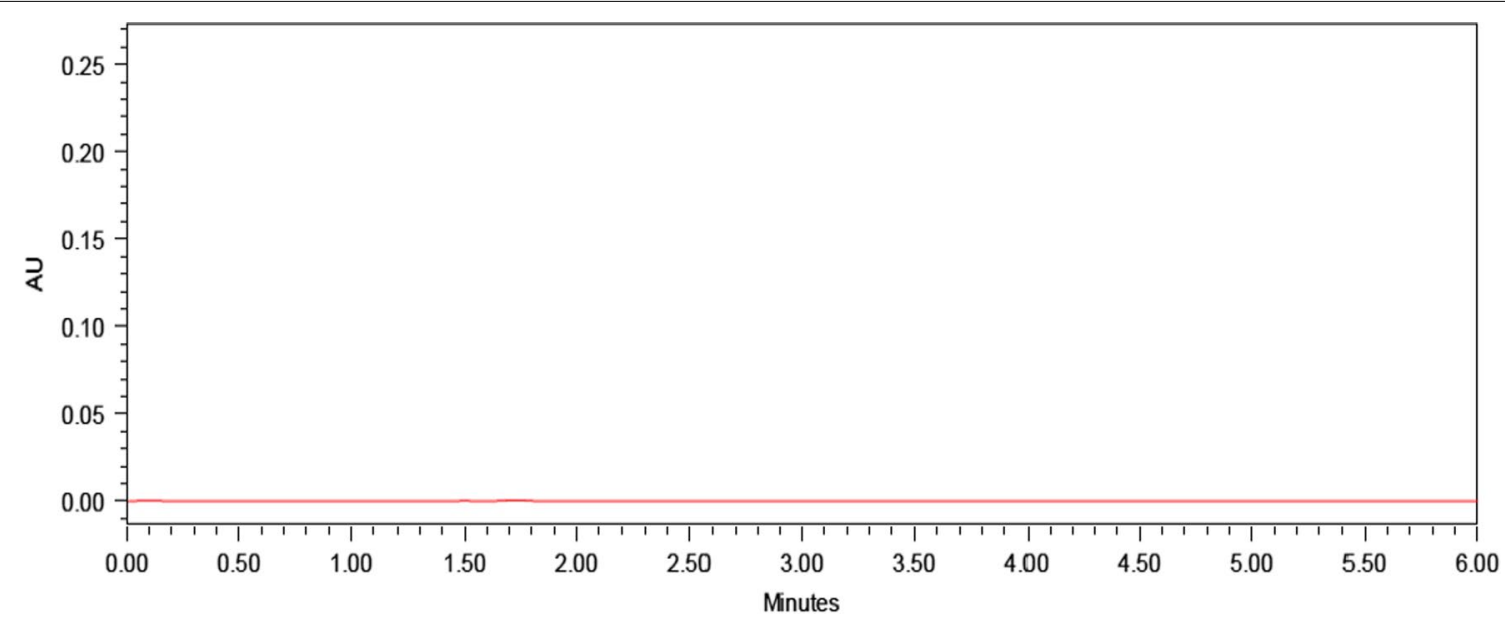

Fig. 3 Blank chromatogram of UPLC 


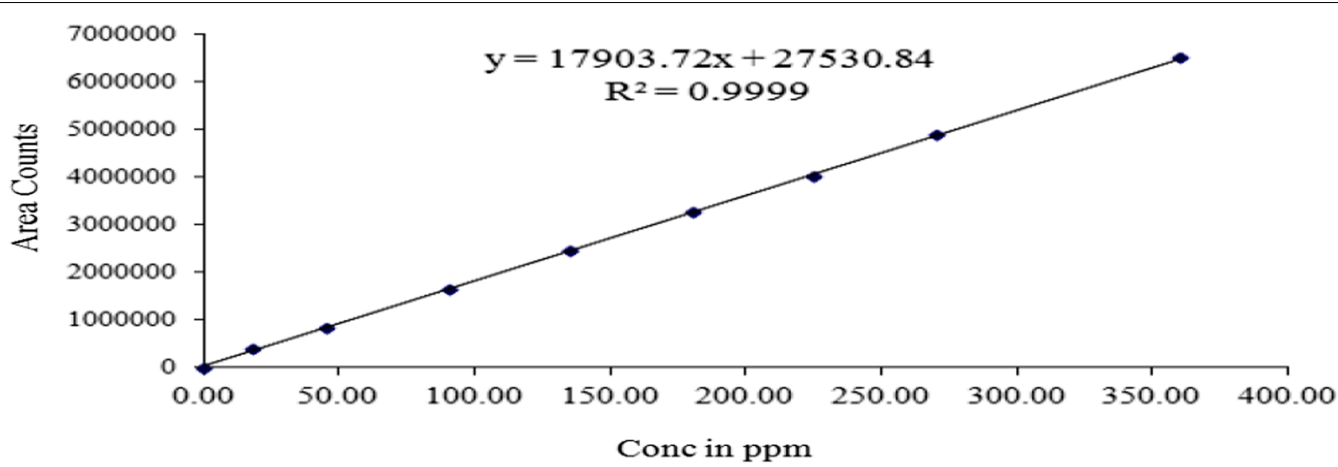

A

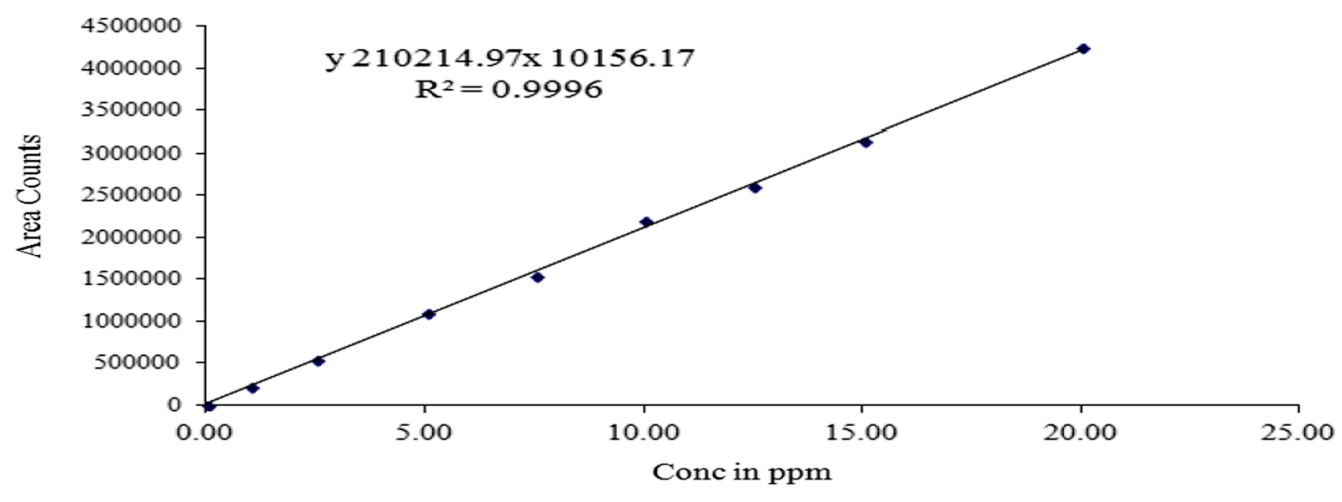

B

Fig. 4 Linearity plots of $\mathbf{A}$ Bempedoic acid and $\mathbf{B}$ Ezetimibe

Table 3 UPLC results of accuracy of (A) Bempedoic acid and (B) Ezetimibe

\begin{tabular}{lcrl}
\hline S. no & $\begin{array}{l}\text { Concentration } \\
(\boldsymbol{\mu} \mathbf{g} / \mathbf{m l})\end{array}$ & Mean \pm SD, \%RSD & $\%$ Recovery \\
\hline$A$ & & & \\
1 & 90 & $90.12 \pm 0.062,0.18$ & 100.1 \\
2 & 180 & $180.06 \pm 0.024,0.39$ & 99.9 \\
3 & 270 & $270 \pm 0.057,0.38$ & 99.6 \\
$B$ & & & \\
1 & 5 & $5.04 \pm 0.039,0.74$ & 99.5 \\
2 & 10 & $10.11 \pm 0.028,0.22$ & 99.3 \\
3 & 15 & $15.05 \pm 0.063,0.52$ & 99.9 \\
\hline
\end{tabular}

accumulation of standard solutions using the developed UPLC method. The LOD values for Bempedoic acid and Ezetimibe were observed as $0.225 \mu \mathrm{g} / \mathrm{mL}$ and $0.013 \mu \mathrm{g} / \mathrm{mL}$ and $\mathrm{s} / \mathrm{n}$ values were 7 and 4 , respectively. LOQ values were $0.743 \mu \mathrm{g} / \mathrm{mL}$ and $0.043 \mu \mathrm{g} / \mathrm{mL}$ and 27 and 21 were the $\mathrm{s} / \mathrm{n}$ values, respectively.

\section{Robustness}

As per ICH norms, deliberate variations were made within the method parameters such as change in flow $( \pm 0.02 \%)$, organic content in the mobile phase $( \pm 10 \%)$, and wavelength of detection $( \pm 5 \mathrm{~nm})$. So there is no tactic capacity to stay unaffected by system suitability. Table 5 shows the robustness of the tactic evaluated by observing the result of the modified parameters on retention time, tailing factor, and content percentage using UPLC. The degree of reliability of the consequences which were obtained by small deliberate variations showed that the tactic was strong.

\section{Stability}

To assess the steadiness of the sample, a solution was analyzed initially for $24 \mathrm{~h}$ at different intervals of time. No significant degradation was observed during this era, and therefore, the mean deviation and mean were not quite $5.0 \%$, suggesting that the solutions were stable for a minimum period of $24 \mathrm{~h}$, which was sufficient for the entire analytical procedure for UPLC. 
Table 4 UPLC precision results of (A) Bempedoic acid and (B) Ezetimibe

\begin{tabular}{|c|c|c|c|}
\hline S. no. & $\begin{array}{l}\text { Amount added }(\mu \mathrm{g} / \\
\mathrm{ml})\end{array}$ & Mean \pm SD & $\%$ RSD \\
\hline \multicolumn{4}{|l|}{ A } \\
\hline \multicolumn{4}{|c|}{ Method precision results } \\
\hline 1 & 90 & $89.98 \pm 0.011$ & 0.36 \\
\hline 2 & 180 & $180.14 \pm 0.053$ & 0.87 \\
\hline 3 & 270 & $270.15 \pm 0.074$ & 0.65 \\
\hline \multicolumn{4}{|c|}{ Intermediate precision results of Day-1 } \\
\hline 1 & 90 & $90.15 \pm 0.046$ & 0.88 \\
\hline 2 & 180 & $180.01 \pm 0.035$ & 0.53 \\
\hline 3 & 270 & $270.08 \pm 0.015$ & 0.27 \\
\hline \multicolumn{4}{|c|}{ Intermediate precision results of Day-2 } \\
\hline 1 & 90 & $90.19 \pm 0.024$ & 0.74 \\
\hline 2 & 180 & $179.99 \pm 0.039$ & 0.65 \\
\hline 3 & 270 & $270.04 \pm 0.055$ & 0.39 \\
\hline \multicolumn{4}{|c|}{ Intermediate precision results of column-1 } \\
\hline 1 & 90 & $90.14 \pm 0.052$ & 0.61 \\
\hline 2 & 180 & $0.07 \pm 0.049$ & 0.36 \\
\hline 3 & 270 & $270.06 \pm 0.078$ & 0.34 \\
\hline \multicolumn{4}{|c|}{ Intermediate precision results of column-2 } \\
\hline 1 & 90 & $90.11 \pm 0.025$ & 0.91 \\
\hline 2 & 180 & $180.07 \pm 0.034$ & 0.68 \\
\hline 3 & 270 & $270.06 \pm 0.048$ & 0.42 \\
\hline \multicolumn{4}{|l|}{ B } \\
\hline \multicolumn{4}{|c|}{ Method precision results } \\
\hline 1 & 5 & $5.09 \pm 0.035$ & 0.74 \\
\hline 2 & 10 & $10.05 \pm 0.024$ & 0.85 \\
\hline 3 & 15 & $15.03 \pm 0.049$ & 0.34 \\
\hline \multicolumn{4}{|c|}{ Intermediate precision results of Day-1 } \\
\hline 1 & 5 & $4.99 \pm 0.024$ & 0.28 \\
\hline 2 & 10 & $10.21 \pm 0.047$ & 0.42 \\
\hline 3 & 15 & $15.14 \pm 0.056$ & 0.53 \\
\hline \multicolumn{4}{|c|}{ Intermediate precision results of Day-2 } \\
\hline 1 & 5 & $5.04 \pm 0.041$ & 0.46 \\
\hline 2 & 10 & $10.17 \pm 0.027$ & 0.62 \\
\hline 3 & 15 & $15.14 \pm 0.011$ & 0.28 \\
\hline \multicolumn{4}{|c|}{ Intermediate precision results of column-1 } \\
\hline 1 & 5 & $5.07 \pm 0.024$ & 0.465 \\
\hline 2 & 10 & $9.97 \pm 0.044$ & 0.61 \\
\hline 3 & 15 & $15.06 \pm 0.021$ & 0.38 \\
\hline \multicolumn{4}{|c|}{ Intermediate precision results of column-2 } \\
\hline 1 & 5 & $5.10 \pm 0.024$ & 0.28 \\
\hline 2 & 10 & $10.07 \pm 0.078$ & 0.11 \\
\hline 3 & 15 & $15.07 \pm 0.039$ & 0.96 \\
\hline
\end{tabular}

\section{Forced degradation studies of Ezetimibe and Bempedoic acid}

According to $\mathrm{ICH}$ stability guidelines, there are various types of forced conditions, i.e., thermal, basic, acidic,
Table 5 Results of robustness of Bempedoic acid and Ezetimibe

\begin{tabular}{lll}
\hline Change in parameter & $\begin{array}{l}\text { \%RSD of Bempedoic } \\
\text { acid }\end{array}$ & $\begin{array}{l}\text { \%RSD of } \\
\text { Ezetimibe }\end{array}$ \\
\hline Flow $(0.8 \mathrm{ml} / \mathrm{min})$ & 1.24 & 1.22 \\
Flow $(1.2 \mathrm{ml} / \mathrm{min})$ & 0.84 & 0.79 \\
Org Phase $(45: 55)$ & 1.36 & 1.65 \\
Org Phase $(55: 45)$ & 0.97 & 0.77 \\
Wavelength $(225 \mathrm{~nm})$ & 0.82 & 0.85 \\
Wavelength $(235 \mathrm{~nm})$ & 0.79 & 0.81 \\
\hline
\end{tabular}

oxidative, photolytic, and reductive forced degradation studies were conducted by using the sample brand name Nexlizet (containing $180 \mathrm{mg}$ of Bempedoic acid and $10 \mathrm{mg}$ of Ezetimibe) (Fig. 5). Seven numbers of DPs, DP1-DP7, were observed and characterized by UPLCMS. The studies provided information about the conditions in which the drug is unstable to avoid potential instabilities; proper measures were often taken during formulation. Tables 6 and 7 represent the degradation results and validation parameters of Bempedoic acid and Ezetimibe.

\section{Acid degradation}

In acid degradation, the selected samples were hydrolyzed with $1 \mathrm{~N} \mathrm{HCl}$ for $3 \mathrm{~h}$ at $60{ }^{\circ} \mathrm{C}, 16.1 \%$ of Bempedoic acid and 12.4\% Ezetimibe degradation was observed using HPLC, and $16.4 \%$ of Bempedoic acid and $11.6 \%$ of Ezetimibe degradation was observed using UPLC, and three degradation products, namely DP1, DP2, and DP5, were formed.

\section{Alkali degradation}

Alkali degradation of selected samples was initiated with $1 \mathrm{~N} \mathrm{NaOH}, 15.2 \%$ of Bempedoic acid and 13.5\% Ezetimibe degradation was observed using HPLC, and $17.7 \%$ of Bempedoic acid, $13.6 \%$ of Ezetimibe was observed using UPLC, and three degradation products, namely DP1, DP2, and DP5, were formed.

\section{Peroxide degradation}

Peroxide decomposition of selected drug sample was studied in $30 \%$ hydrogen peroxide, $18.7 \%$ of Bempedoic acid and $15.8 \%$ of Ezetimibe degradation was observed using UPLC, and four degradation products, namely DP1, DP2, DP5, and DP7, were formed.

\section{Reduction degradation}

Reduction degradation of selected drugs was studied in $30 \%$ sodium bisulfate solution, $18.5 \%$ of Bempedoic acid and $16.4 \%$ of Ezetimibe degradation was observed using UPLC, and one DP1 degradation product was formed. 


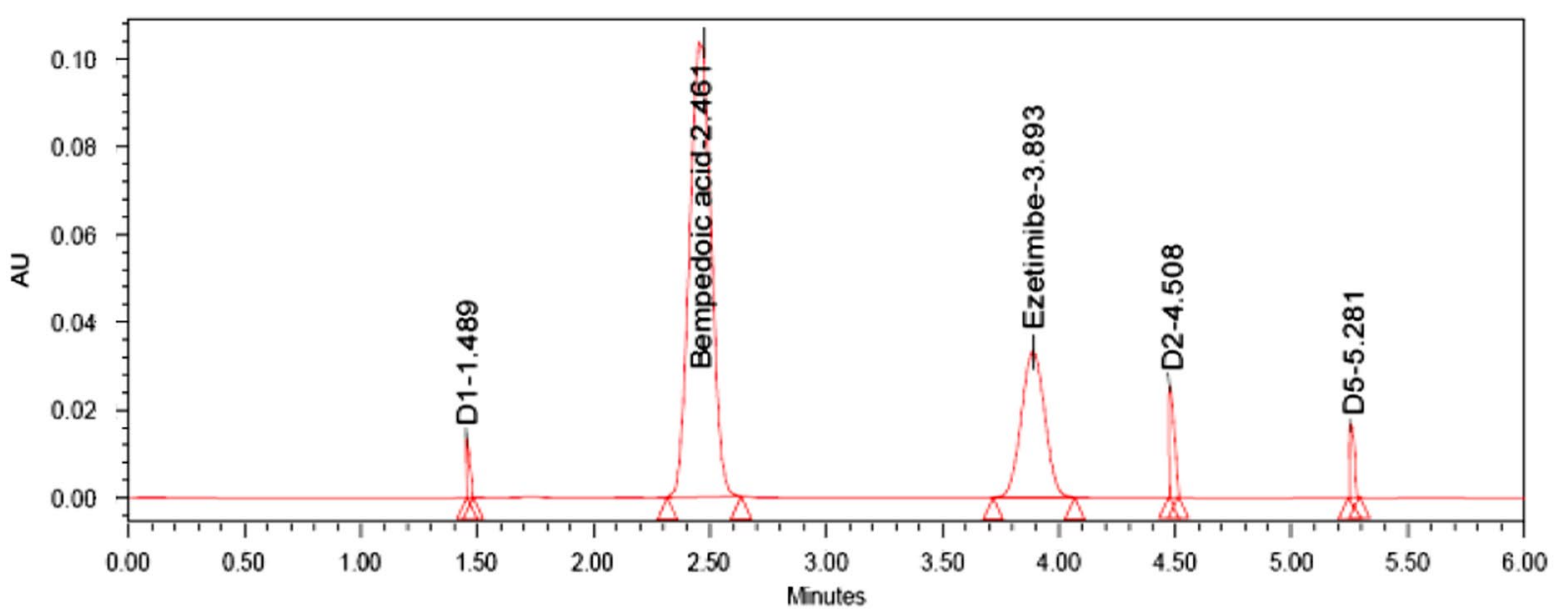

UPLC Acid degradation

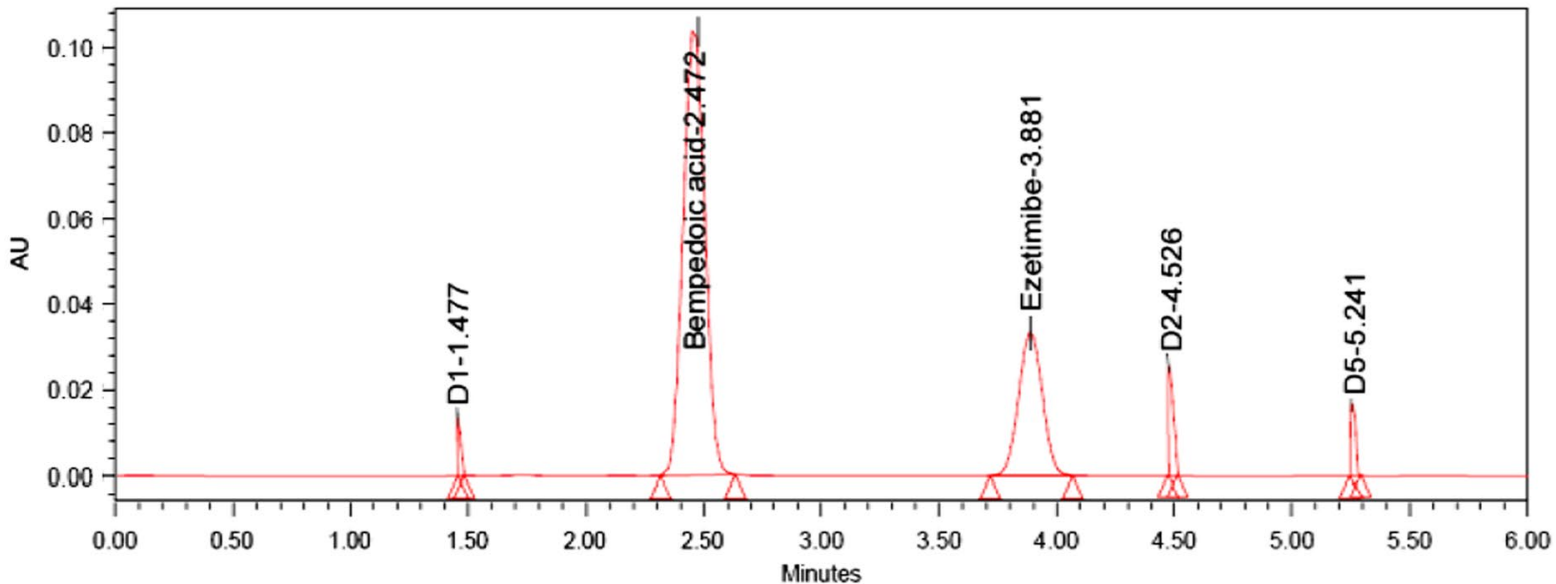

UPLC Alkali degradation

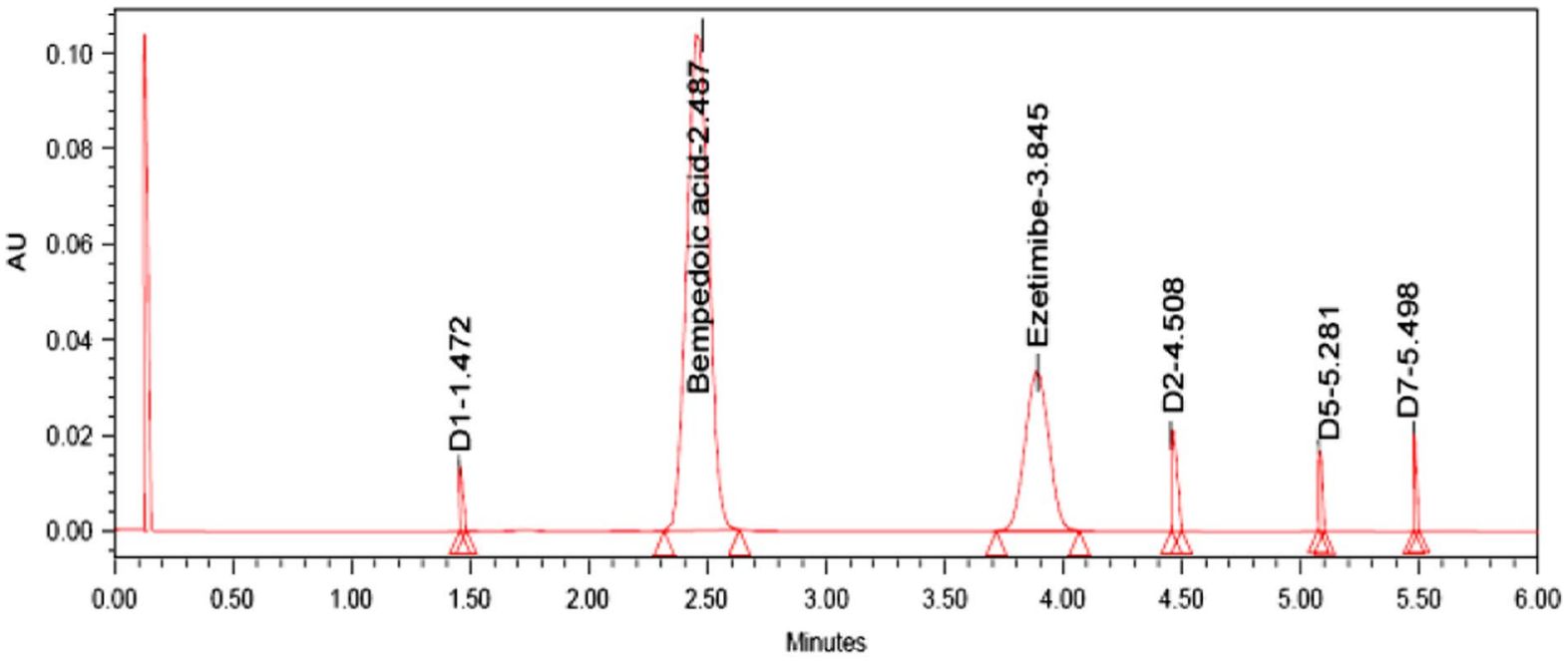

UPLC Peroxide degradation

Fig. 5 UPLC degradation chromatograms 


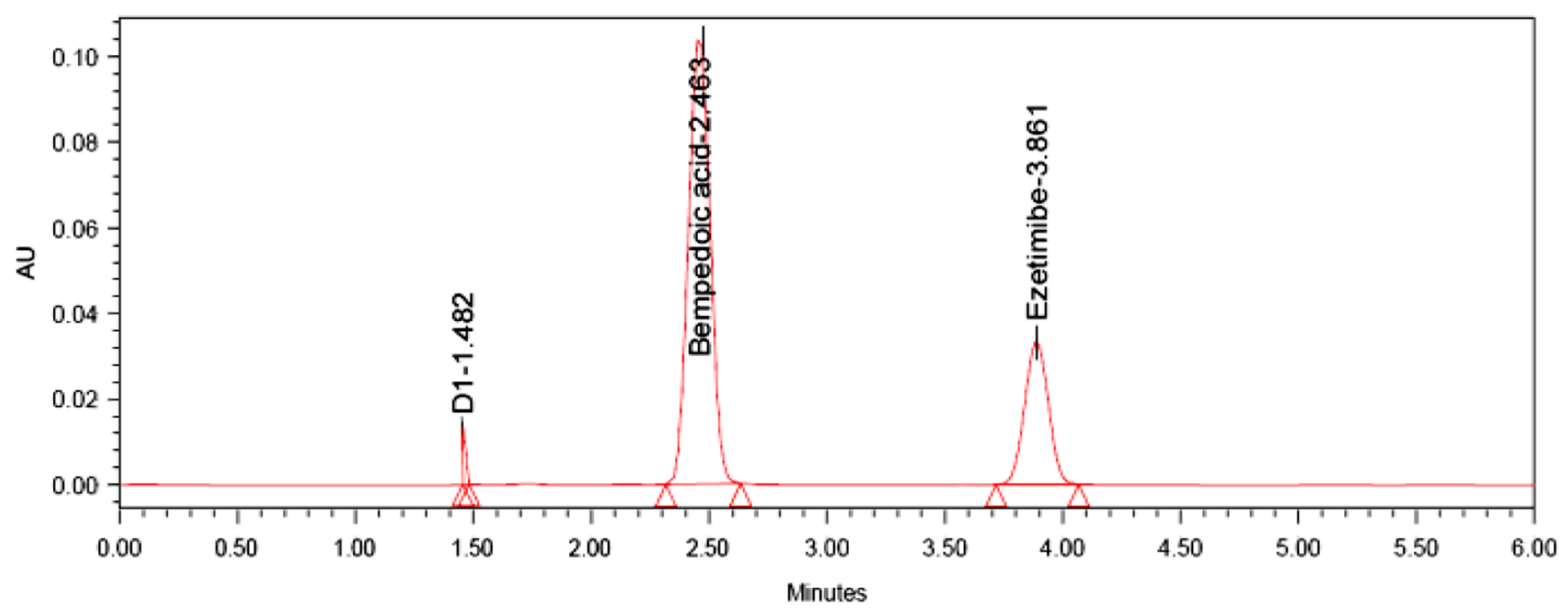

UPLC Reduction degradaiton

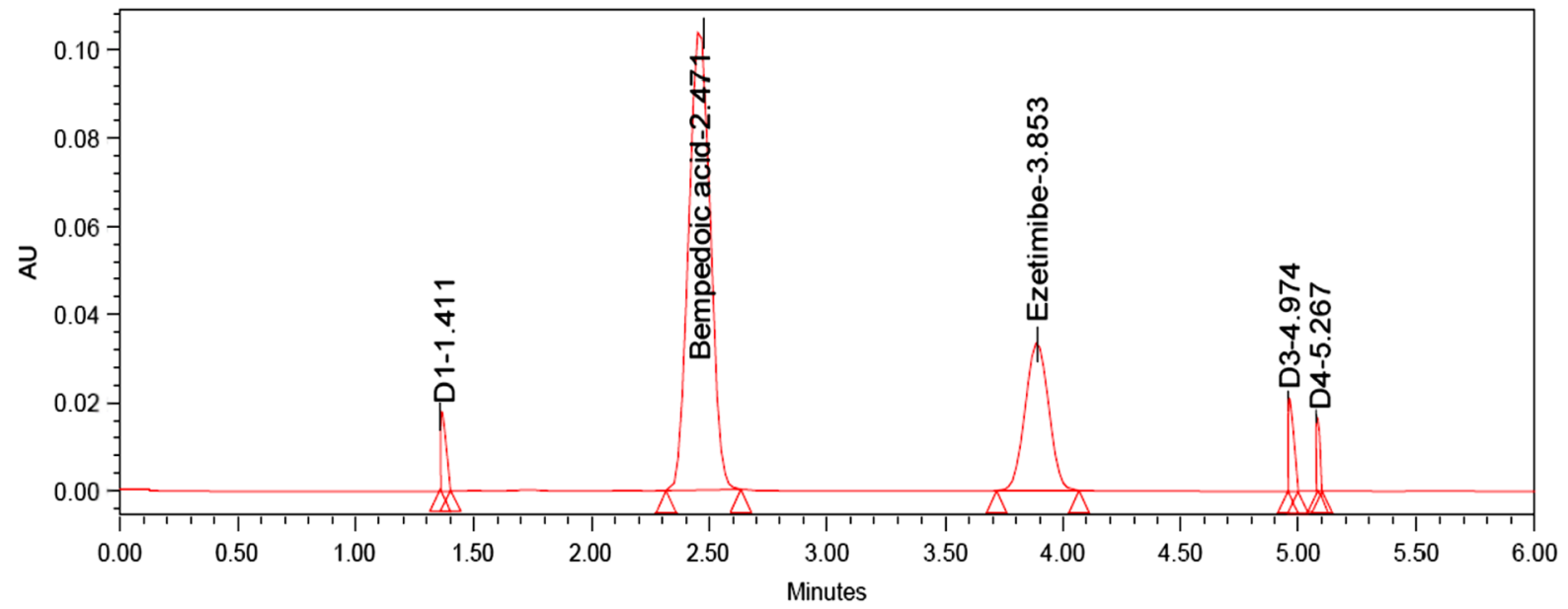

UPLC Photo degradation

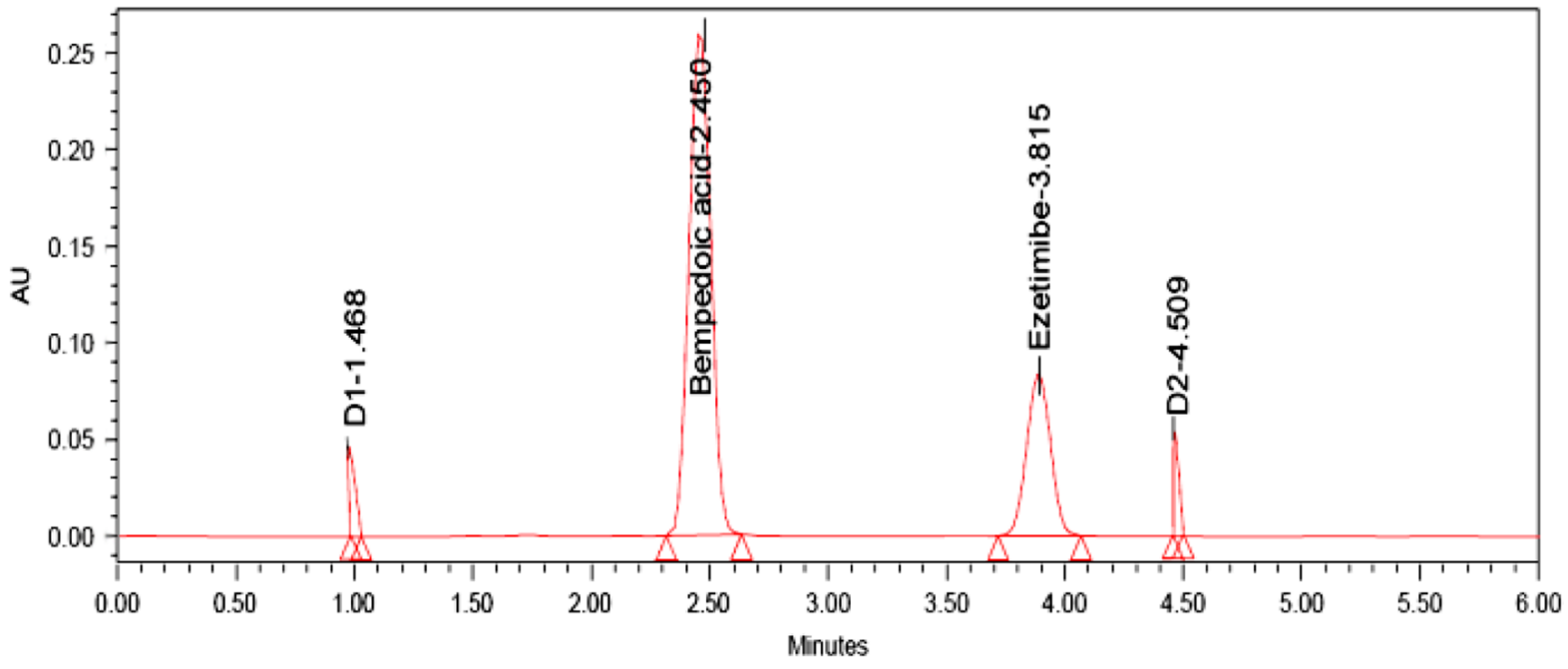

UPLC Thermal degradation

Fig. 5 continued 
Table 6 Degradation results of Bempedoic acid and Ezetimibe

\begin{tabular}{|c|c|c|c|c|c|c|c|c|}
\hline \multirow[t]{2}{*}{ Deg condition } & \multirow[t]{2}{*}{ Time/Temp } & \multicolumn{3}{|c|}{ Bempedoic acid } & \multicolumn{3}{|c|}{ Ezetimibe } & \multirow[t]{2}{*}{ Number of DPs formec } \\
\hline & & $\%$ Deg & $\%$ Assay & $\% \mathrm{MB}$ & $\%$ Deg & $\%$ Assay & $\% \mathrm{MB}$ & \\
\hline Acid deg & $3 \mathrm{~h}, 60^{\circ} \mathrm{C}$ & 16.4 & 86.1 & 102.5 & 11.6 & 89.6 & 101.2 & DP1, DP2 and DP5 \\
\hline Alkali deg & $3 \mathrm{~h}, 60^{\circ} \mathrm{C}$ & 17.7 & 81.8 & 99.5 & 13.6 & 87.2 & 100.8 & DP1, DP2 and DP5 \\
\hline Peroxide deg & - & 18.7 & 81.2 & 99.9 & 15.8 & 84.1 & 99.9 & DP1, DP2, DP5 and DP7 \\
\hline Reduction deg & $3 \mathrm{~h}, 60^{\circ} \mathrm{C}$ & 18.5 & 83.4 & 101.9 & 16.4 & 84.7 & 101.1 & DP1 \\
\hline Thermal deg & $24 \mathrm{~h}, 105^{\circ} \mathrm{C}$ & 16.3 & 85.3 & 101.6 & 16.6 & 84.8 & 101.4 & DP1 and DP2 \\
\hline Photolytic deg & UV-Vis light & 16.2 & 83.5 & 99.7 & 16.8 & 83.9 & 100.7 & DP1, DP3 and DP4 \\
\hline
\end{tabular}

Table 7 Method validation results of Bempedoic acid and Ezetimibe by UPLC

\begin{tabular}{|c|c|c|c|c|}
\hline \multirow[t]{2}{*}{ Parameter } & \multicolumn{2}{|l|}{ Bempedoic acid } & \multicolumn{2}{|l|}{ Ezetimibe } \\
\hline & Concentration $(\mu \mathrm{g} / \mathrm{ml})$ & Result & Concentration $(\mu \mathrm{g} / \mathrm{ml})$ & Result \\
\hline Linearity & $18-360$ & CC: 0.999 & $1-20$ & CC: 0.999 \\
\hline \multirow[t]{3}{*}{ Accuracy } & 90 & \% Rec: 100.1 & 5 & \%Rec: 99.5 \\
\hline & 180 & \%Rec: 99.9 & 10 & \% Rec: 99.3 \\
\hline & 270 & \% Rec: 99.6 & 15 & \% Rec: 99.9 \\
\hline Intraday precision & 180 & \%RSD: 0.87 & 10 & \%RSD: 0.65 \\
\hline Interday precision & 180 & \%RSD: 0.36 & 10 & \%RSD: 0.61 \\
\hline \multicolumn{5}{|l|}{ Robustness } \\
\hline $\begin{array}{l}\text { Flow Plus } \\
\text { Flow Minus }\end{array}$ & $\begin{array}{l}180 \\
180\end{array}$ & $\begin{array}{l}0.41 \\
0.37\end{array}$ & $\begin{array}{l}10 \\
10\end{array}$ & $\begin{array}{l}0.33 \\
0.82\end{array}$ \\
\hline Organic Plus & 180 & 0.78 & 10 & 0.51 \\
\hline Organic Minus & 180 & 0.52 & 10 & 0.78 \\
\hline Wavelength Plus & 180 & 0.42 & 10 & 0.84 \\
\hline Wavelength Minus & 180 & 0.39 & 10 & 0.92 \\
\hline
\end{tabular}

CC correlation coefficient

$\%$ REC-\% Recovery

\%RSD: Relative standard deviation

\section{Thermal degradation}

The thermal degradation sample was exposed at $105{ }^{\circ} \mathrm{C}$ for 6 h, 16.3\% of Bempedoic acid and 16.6\% of Ezetimibe degradation was observed in UPLC, and two degradation products, namely DP6 and DP2, were formed.

\section{Photolytic degradation}

The sample was exposed to sunlight for $12 \mathrm{~h}, 16.2 \%$ of Bempedoic acid and $16.8 \%$ of Ezetimibe degradation was observed using UPLC, and three degradation products, namely DP1, DP3, and DP4, were formed.

\section{Collision-induced dissociation of Bempedoic acid and Ezetimibe}

DP1: Scheme 1 shows the fragmentation mechanism of DP1, and the ESI spectrum showed the most intense [ $\mathrm{M}+\mathrm{H}]+$ ion of $\mathrm{m} / \mathrm{z}-449$, which was observed under acid, alkali, peroxide, and photolytic degeneration conditions.
The MS/MS spectrum of DP1 displayed abundant product ions at m/z-361 (loss of C4H8O2), m/z-273 (loss of $\mathrm{C} 4 \mathrm{H} 8 \mathrm{O} 2$ from $\mathrm{m} / \mathrm{z}$ 361), and $\mathrm{m} / \mathrm{z}-157$ (loss of $\mathrm{C} 6 \mathrm{H} 12 \mathrm{O} 6$ from $\mathrm{m} / \mathrm{z}$ 273). The MS/MS experiments combined with accurate mass measurements have confirmed the proposed scheme. Figures S6 and S7 represents collision induced dissociation of Bempedoic acid and Ezetimibe and MS spectral data.

DP2: Scheme 2 shows the fragmentation mechanism of Ezetimibe DP2, and the MS/MS spectrum showed more intense $[\mathrm{M}+\mathrm{H}]$ ion of $\mathrm{m} / \mathrm{z}-373$, which was noticed under acid, alkali, thermal, and peroxide conditions. The spectrum displayed abundant product ions at $\mathrm{m} / \mathrm{z}-295$ (loss of benzene), $\mathrm{m} / \mathrm{z}-217$ (loss of benzene from $\mathrm{m} / \mathrm{z} 292$ ), $\mathrm{m} / \mathrm{z}-123$ (loss of phenol from $\mathrm{m} / \mathrm{z} 217$ ), and $\mathrm{m} / \mathrm{z}-63$ (loss of $\mathrm{C}_{3} \mathrm{H}_{8} \mathrm{O}$ from $\mathrm{m} / \mathrm{z}$ 123). The MS/MS experiments combined with correct mass evaluations have confirmed the proposed scheme. 
DP3: Scheme 3 shows the fragmentation mechanism DP3 of $\mathrm{m} / \mathrm{z} 427$ with molecular formula $\mathrm{C}_{24} \mathrm{H}_{23} \mathrm{~F}_{2} \mathrm{NO}_{4}$, which was noticed under photolytic conditions. The MS spectrum displays abundant product ions at $\mathrm{m} / \mathrm{z}-274$ (loss of $\mathrm{C}_{9} \mathrm{H}_{11} \mathrm{OF}$ ), $\mathrm{m} / \mathrm{z}-179$ (loss of $\mathrm{m} / \mathrm{z} \mathrm{C}_{6} \mathrm{H}_{5} \mathrm{~F}$ from $\mathrm{m} / \mathrm{z}$ 274), $\mathrm{m} / \mathrm{z}$-93 (loss of $\mathrm{C}_{3} \mathrm{H}_{8} \mathrm{O}$ from $\mathrm{m} / \mathrm{z} 153$ ), and $\mathrm{m} / \mathrm{z}-85$ (loss of phenol from $\mathrm{m} / \mathrm{z}$ 179). The MS/MS measurements combined with correct mass evaluations have confirmed the proposed scheme.

DP4 : Scheme 4 shows the fragmentation mechanism for DP4 of $\mathrm{m} / \mathrm{z}-499$, which was noticed under photolytic degradation condition. The spectrum displays abundant product ions at $\mathrm{m} / \mathrm{z}-346$ (loss of $\mathrm{C}_{9} \mathrm{H}_{11} \mathrm{OF}$ ), $\mathrm{m} / \mathrm{z}-173$ (loss of $\mathrm{m} / \mathrm{z} \mathrm{C}_{6} \mathrm{H}_{5} \mathrm{~F}$ from $\mathrm{m} / \mathrm{z}$ 346), $\mathrm{m} / \mathrm{z}-93$ (loss of $\mathrm{m} / \mathrm{z} \mathrm{C}_{3} \mathrm{H}_{8} \mathrm{O}$ from $\mathrm{m} / \mathrm{z}-153$ ), and $\mathrm{m} / \mathrm{z}$-93 (loss of $\mathrm{C}_{7} \mathrm{H}_{8} \mathrm{O}$ from $\mathrm{m} / \mathrm{z}$ 173). The MS/MS experiments combined with correct mass evaluations have confirmed the proposed scheme.

DP5: Scheme 5 shows the fragmentation mechanism for DP5 of m/z-393.4, which was noticed under acid, alkali, and peroxide degradation conditions. The spectrum displays abundant product ions at $\mathrm{m} / \mathrm{z}-137$ (loss of $\mathrm{C}_{9} \mathrm{H}_{11} \mathrm{~F}$ ), $\mathrm{m} / \mathrm{z}-95$ (loss of $\mathrm{C}_{6} \mathrm{H}_{5} \mathrm{~F}$ from $\mathrm{m} / \mathrm{z} 256$ ), and $\mathrm{m} / \mathrm{z}-94$ (loss of $\mathrm{C}_{6} \mathrm{H}_{5} \mathrm{OH}$ from $\left.\mathrm{m} / \mathrm{z} 161\right)$. The MS/MS experiments combined with correct mass evaluations have confirmed the proposed scheme.

DP6: Scheme 6 shows the fragmentation mechanism for DP6 of $\mathrm{m} / \mathrm{z}-154$, which was noticed under thermal degradation condition. The spectrum displays abundant product ions at $\mathrm{m} / \mathrm{z}-72$ (loss of $\mathrm{C}_{6} \mathrm{H}_{12}$ ) and $\mathrm{m} / \mathrm{z}-84$ (loss of $\mathrm{C}_{5} \mathrm{H}_{12}$ ). The MS/MS experiments combined with correct mass evaluations have confirmed the proposed scheme

DP7: Scheme 7 shows the fragmentation mechanism of degradation product 7 of $\mathrm{m} / \mathrm{z}-493$, which was noticed under peroxide degradation condition. The spectrum displays abundant product ions at $\mathrm{m} / \mathrm{z}-399$ (loss of $\mathrm{C}_{6} \mathrm{H}_{5} \mathrm{~F}$ ), $\mathrm{m} / \mathrm{z}$-359 (loss of $\mathrm{C}_{8} \mathrm{H}_{8} \mathrm{O}_{2}$ from m/z-493), $\mathrm{m} / \mathrm{z}-265$ (loss of $\mathrm{C}_{6} \mathrm{H}_{5} \mathrm{~F}$ from m/z-359), $\mathrm{m} / \mathrm{z}-205$ (loss of $\mathrm{C}_{11} \mathrm{H}_{14} \mathrm{FO}_{2}$ from $\mathrm{m} / \mathrm{z}-399$ ), and $\mathrm{m} / \mathrm{z}-71$ (loss of $\mathrm{C}_{11} \mathrm{H}_{14} \mathrm{FO}_{2}$ from $\mathrm{m} / \mathrm{z}-265$ ). The MS/MS experiments combined with correct mass evaluations have confirmed the proposed scheme.

\section{Discussion}

We have developed a responsive, robust, and fast UPLC process. The factors influencing the efficiency of the system were optimized, and the resulting method displayed high sensitivity and selectivity. A literature survey found that little attention was paid to the structural elucidation of the degradation products (DPs) of Bempedoic acid and Ezetimibe. A few attempts have been made for major impurities. According to the ICH stability guidelines [24-28], there are different forms of forced conditions, i.e., thermal, basic, acidic, oxidative, photolytic, and reductive forced degradation studies have been conducted [29-34]. Thus, in continuation of our previous efforts $[35,36]$, seven DPs $\left(\mathrm{DP}_{1}-\mathrm{DP}_{7}\right)$ were observed and characterized by UPLC-MS, and few articles were mentioned in the last few years for quantification and analysis of Bempedoic acid and Ezetimibe in various chemical and biological matrices by using HPLC, UPLC, and characterization of its degradation products [37-44]. In the present study, we intended to explore a specific, sensitive, and new UPLC method toward the analysis of Bempedoic acid, Ezetimibe, and characterization of its new degradation products by UPLC-MS.

\section{Conclusions}

In this study, a unique, simple, rapid, economical, sensitive, and simply available UPLC technique was developed for the coincident determination of Bempedoic acid and Ezetimibe in bulk and tablet dosage form. The advantages of this method are shorter run time, low price, accessibility, reliability, sensitivity, and reproducibility. The degradation actions of the drugs were examined under hydrolysis (acid, base, and neutral), oxidation, and photolytic and thermal stress conditions. The drugs were found to be stable in thermal hydrolysis and unstable in acid, alkali, and oxidative conditions. The degradation products were identified $[\mathrm{M}+\mathrm{H}]^{+}$ion, and the proposed structures were supported by UPLC-MS/MS experiments combined with correct mass evaluations. The UPLC method was supported as per ICH guidelines and finally applied to the marketed formulations.

\section{Abbreviations}

UPLC: Ultra-performance liquid chromatography; LOD: Limit of detection; LOQ: Limit of quantization; ICH: International Council for Harmonization; UPLC-MS: Ultra-performance liquid chromatography-mass spectrometry.

\section{Supplementary Information}

The online version contains supplementary material available at https://doi. org/10.1186/s43094-021-00381-6.

Additional file 1. Collision induced dissociation of Bempedoic acid and Ezetimibe and Mass spectral data.

\section{Acknowledgements}

The authors are grateful to the Acharya Nagarjuna University for providing facilities to complete the research work.

\section{Authors' contributions}

SMT and AV designed the study, performed the method development and validation, wrote the protocol, and wrote the first draft of the manuscript. CHR helped in the analyses of the study and literature searches. All authors read and approved the final manuscript. 


\section{Funding}

Not applicable.

\section{Availability of data and materials}

The data for verification are provided with a supplementary file, and the rest of the data, if required, will be available upon request.

\section{Declarations}

Ethics approval and consent to participate

Not applicable.

\section{Consent for publication}

Not applicable.

\section{Competing interests}

The authors declare that they have no competing interests.

\section{Author details}

${ }^{1}$ Department of Chemistry, Vignan Degree College, Guntur, AP 522009, India. ${ }^{2}$ Department of Chemistry, Acharya Nagarjuna University, Nagarjuna Nagar, Guntur, AP 522510, India. ' ${ }^{3}$ Department of Chemistry, Sir C R Reddy College, Eluru, AP 534007, India. ${ }^{4}$ Department of Chemistry, Vignan's NIRULA Institute of Technology \& Science, Guntur, AP 522009, India.

Received: 27 August 2021 Accepted: 16 November 2021 Published online: 04 December 2021

\section{References}

1. Bhatnagar D, Soran H, Durrington PN (2008) Hypercholesterolemia and its management. BMJ 337-a993

2. Awad K, Mikhailidis DP, Katsiki N, Muntner P, Banach M (2018) Effect of ezetimibe monotherapy on plasma lipoprotein concentrations in patients with primary hypercholesterolemia. A systematic review and meta-analysis of randomized controlled trials. Drugs 78(4):453-462

3. Zech LA Jr, Hoeg JM (2008) Correlating corneal arcus with atherosclerosis in familial hypercholesterolemia. Lipids Health Dis 7(1):7

4. Martin C, Samuel C, David WR, Andrew P, Smith H, Fowler K (2006) Assigning sex to pre-adult stalk-eyed flies using general disc morphology and $X$ chromosome zygosity. BMC Dev Biol 6(1):29

5. Scientific steering committee on behalf of the Simon Broome register group Mortality in treated hetero zygous familial hypercholesterolaemia (1999). Atherosclerosis 142(1):105-112

6. Marais AD, Blom DJ, Firth JC (2002) Statins in homozygous familial hypercholesterolaemia. Curratheroscler rep 4(1):19-25

7. Faxon DP, Creager MA, Smith SC, Pasternak RC, Olin JW, Bettmann MA, Cirqui MH, Milani RV, Loscalzo J, Kaufman JA, Jones DW, Pearce WH (2004) Atherosclerotic vascular disease conference. Executive disease summary. Atherosclerotic vascular disease conference proceedings for health care professionals from a special writing group of the American heart association. Circulation 109(21):2595-604

8. Zhao DF, Edelman JJ, Seco M, Bannon PG, Wilson MK, Byrom MJ, Thourani V, Lamy A, Taggart DP, Puskas JD, Vallely MP (2017) Coronary artery bypass grafting with and without manipulation of the ascending aorta. A network meta-analysis. J Am Coll Cardiol 69(8):924-936

9. Dashty M, Motazacker MM, Levels J, de Vries M, Mahmoudi M, Peppelenbosch MP, Razaee F (2014) Proteome of human plasma very low density lipoprotein and low density lipoprotein exhibits a link with coagulation and lipid metabolism. Thromb Haemost 111(3):518-530

10. Ahotupa M (2017) Oxidized lipoprotein lipids and atherosclerosis. Free Radical Res 51(4):439-447

11. Robinson PC, Stamp LK (2016) Management of gout. Must has changed. Aust Family Phys 45(5):299-302

12. Choi HK (2010) A prescription for lifestyle changes in patients with hyperuricemia and gout. Curropinrheumatol 22(2):165-172

13. Helander HF, Fandrinks L (2014) Surface area of the digestive tract-revisited. Scand J Gastroenterol 49(6):681-689
14. Dupont HL (2014) Acute infectious diarrhea in immune competent adults. New Engl J Med. 370(16):1532-1540

15. Sweetser S (2012) Evaluating the patients with diarrhea. A case based approach. Mayo Clin Proc 87(6):596-602

16. Thomas JR, Lawton JN (2017) Biceps and triceps ruptures in athletes. Hand Clin 33(1):35-46

17. Wu Y, Lin L, Li H, Zhao Y, Liu L, Jia Z, Wang D, He Q, Ruan D (2016) Is surgical intervention more effective than non surgical treatment for acute Achilles tendon rupture. A systematic review of overlapping Meta-analyzes. Int J Surg 36(Pt A):305-311

18. Taylor FC, Huffman M, Ebrahim S (2013) Statin therapy for primary prevention of cardiovascular disease. JAMA 310(22):2451-2452

19. Abd TT, Jacobson TA (2011) Statin induced myopathy. A review and update. Expert Opin Drug Saf 10(3):373-387

20. Sampson HA, Munoz Furlong A, Campbell RL, Adkinson Jr N F, Bock S A, Branum A, Camargo Jr CA, Cydulka R, Galli SJ, Gidudu J, Gruchalla RS, Harlor Jr AD, Hepner DL, Lewis LM, Lieberman PL, Metcalfe DD, O'Connor R, Muraro A, Rudman CS, Scherrer D, Simons FER, Thomas S, Wood JP, Decker WW (2006) Second symposium on the definition and management of anaphylaxis. Summary report-Second national institute of allergy and infectious disease/food allergy and anaphylaxis network symposium. J Allergy Clin Immunol 117(2):391-7

21. Tejedor-Alonso MA, Moro-Moro M, Mugica-garcia MV (2015) Epidemiology of anaphylaxis, Contributions from the last 10years. J Investig Allergol Clin Immunol 25(3):163-175

22. Kremer KP, Kremer TR (2018) Breastfeeding is associated with decreased childhood maltreatment. Breastfeed Med 13(1):18-22

23. Spencer B, Wambach K, Domain EW (2015) African American women's breastfeeding experiences, cultural, personal and political voices. Qual Health Res 25(7):974-987

24. ICH validation of analytical procedures methodology

25. Validation of compendia methods. United States pharmacopeia, 2003, $21^{\text {st }}$ edition, 2440

26. International Conference on Harmonization. Validation of analytical procedures: methodology ICH Q2 (R1)2005. http://www.ich.org/filea dmin/Public Web Site/ICH Products/Guidelines/Quality/Q2 R1/Step4/ Q2R1Guideline.pdf

27. $22 \mathrm{ICH}$ (2003) Q1A (R2) Stability testing of new drug substances and products. https://www.ich.org/fileadmin/Public_Web_Site/ICH_Produ cts/Guidelines/Quality/Q1A_R2/Step4/Q1A_R2_Guideline.pdf

28. 2 ICH (1997) Q1B Stability testing: Photostability testing of New drug substances and products.https://www.ich.org/fileadmin/Public_Web_ Site/ICH_Products/Guidelines/Quality/Q1B/Step4/Q1B_Guideline.pdf

29. Narasimha SL, Chandrasekar K, Srinivas KS, Ravi teja Y, (2020) Separation and characterization of new forced degradation products of dasatinib in tablet dosage formulation using LC-MS and stability-indicating HPLC methods. Chromatographia 83(6):947-962

30. Zhuang T, Wang G, Cui X, Chen Y, Chen L, Zhang G (2016) Isolation and structure characterization of two novel degradation products in Flupirtine maleate formulation by prep-HPLC, LC-MS/Q-TOF and 2D-NMR. Chromatographia 79(5):1041-1047

31. Zaman B, Hassan W (2018) Development of stability indicating HPLC-UV method for determination of daclatasvir and characterization of forced degradation products. Chromatographia 81(3):785-797

32. Santa Z, Koti J, Szoke K, Vukics K, Szanta J (2002) Structure of the major degradant of Ezetimibe. J Pharm Biomed Anal 11(11):1587-1664

33. Prasad K, Venkatappaiah V, Pallavi A, Saeed SA, Mukanti K, Parthasaradhi D (2016) LC-MS/MS characterization of the forced degradation products of Ezetimibe: development and validation of a stability-indicating UPLC method. J Taibah Univ Sci 10(1):148-160

34. Saranjit S, Baljinder S, Rakesh B, Lalit W, Rahul S (2006) Stress degradation studies on Ezetimibe and development of a validated stability-indicating HPLC assay. J Pharm Biomed Anal 41(3):1037-1040

35. Subrahmanyam T, Anuradha V, Prathyusha KA (2021) New validated RPHPLC method for cisplatin and topotecan in API and vaccine form and its stress studies. Int J Res Pharm Sci 12(1):808-814

36. Subrahmanyam T, Anuradha V, Murthy SNB, Prathuyasa KA (2021) A newly developed reverse phase-high performance liquid chromatography method for the assay of dexmethylphenidate and serdexmethylphenidate with PDA. J Pharm Res Int 33(31B):203-211 
37. Elawady T, Ibrahim F, Khedr A, Belal F (2021) Simultaneous determination of Ezetimibe, atorvastatin and Simvastatin using quadrupole LC-MS application to combined tablets and plasma after SPE. Acta Chromatogr 33(3):245-252

38. Li Y, Tang L, Wang Y (2021) Simultaneous quantification of Ezetimibe and Ezetimibe glucuronide in human plasma: a pharmacokinetic study in healthy Chinese volunteers. Lat Am J Pharm 40(4):735-741

39. Devi DPV, Narayanarao KMV, Shyamala P, Krishna RM, Prasad KS (2020) HPLC estimation of new impurity methyl Ezetimibe in Ezetimibe drug. Asian J Chem 32(6):1309-1313

40. Ramadevi P, Rambabu K (2020) Bio analytical method development and validation for Ezetimibe and pitavastain and its applications to pharmacokinetic studies in rabbit plasma by using LC-MS/MS. Int J Res Pharm Sci 11(4):7854-7862

41. Kurbanoglu S, Esim O, Ozkan CK, Savaser A, Ozkan Y, Uslu B, Ozkan SA (2020) Stability-indicating liquid chromatographic method for the simultaneous determination of Rosuvastatin and Ezetimibe from pharmaceuticals and biological samples. J Turk Chem Soc Sect A Chem 7(3):865-874

42. Li Y, Tang L, Wang Y (2020) A sensitive and reliable method for the determination of Ezetimibe by $\mathrm{lc}-\mathrm{ms} / \mathrm{ms}$ and its application to a pharmacokinetic study in healthy Chinese volunteers. Latin Am J Pharm 39(10):1921-1926

43. Shah U, Shah K, Patel R (2019) Stability-indicating analytical method development using quality by design approach for simultaneous estimation of Ezetimibe and glimepiride. Indian J Pharm Sci 81 (2):273-281

44. Kurbanoglu S, Esim O, Ozkan CK, Savaser A, Ozkan Y, Ozkan SA (2019) Development and validation of RP-LC method for the simultaneous determination of simvastatin and ezetimibe in fixed-dose combination tablets and in rabbit serum. Chromatographia 82(1):279-285

\section{Publisher's Note}

Springer Nature remains neutral with regard to jurisdictional claims in published maps and institutional affiliations.

\section{Submit your manuscript to a SpringerOpen ${ }^{\circ}$ journal and benefit from:}

- Convenient online submission

- Rigorous peer review

- Open access: articles freely available online

- High visibility within the field

Retaining the copyright to your article 